\section{Prolonged SARS-CoV-2 RNA Shedding from Therapy Cat after Cluster Outbreak in Retirement Home}

Claudia Schulz, ${ }^{1}$ Claudia Wylezich, ${ }^{1}$ Kerstin Wernike, Magdalena Gründl, Alexandra Dangel, Christine Baechlein, Donata Hoffmann, Susanne Röhrs, Sabrina Hepner, Nikolaus Ackermann, Andreas Sing, Isabelle Pink, Beate Länger, Holger A. Volk, Paul Becher, Gerd Sutter, Antonie Neubauer-Juric, Maren von Köckritz-Blickwede, Martin Beer, Asisa Volz

Author affiliations: University of Veterinary Medicine Hanover, Hanover, Germany (C. Schulz, C. Baechlein, S. Röhrs,

B. Länger, H.A. Volk, P. Becher, M. von Köckritz-Blickwede, A. Volz); Friedrich-Loeffler-Institut, Greifswald-Insel Riems, Germany (C. Wylezich, K. Wernike, D. Hoffmann, M. Beer); Local Health Authority Cham, Cham, Germany (M. Gründl); Bavarian Health and Food Safety Authority, Oberschleißheim, Germany (A. Dangel, S. Hepner, N. Ackermann, A. Sing, A. NeubauerJuric); Hanover Medical School, Hanover (I. Pink);

Ludwig Maximilian University Munich, Munich, Germany (G. Sutter)

DOI: https://doi.org/10.3201/eid2707.204670

We report a therapy cat in a nursing home in Germany infected with severe acute respiratory syndrome coronavirus 2 during a cluster outbreak in the home residents. Although we confirmed prolonged presence of virus RNA in the asymptomatic cat, genome sequencing showed no further role of the cat in human infections on site.

Cats are susceptible to severe acute respiratory syndrome coronavirus 2 (SARS-CoV-2) infection and can transmit the virus to other cats (1-3). However, the pathophysiology and epidemiologic impact of SARS-CoV-2 infection of pets remain poorly understood (4). We report 3 therapy cats living in a retirement home in Germany for which evidence indicated naturally occurring human-to-cat transmission during SARS-CoV-2 outbreaks.

A total of 21 confirmed human SARS-CoV-2 infections occurred in the outbreaks, including 3 deaths. Six infected care and administrative personnel showed mild or no symptoms; 15 infected residents showed typical signs of coronavirus disease, including fever and severe respiratory disease (cough, pneumonia, and dyspnea). The first outbreak occurred on the home's ground floor at the end of March 2020 (Appendix Figure 1, panel A, https://wwwnc.cdc.gov/

${ }^{1}$ These authors contributed equally to this article.
EID/article/27/7/20-4670-App1.pdf); it is assumed that the virus was introduced through care personnel. One SARS-CoV-2-positive resident (90 years of age, given a diagnosis on April 4, 2020), already bedridden, died on April 12. He had been in close contact with cat K8, which snuggled in his face.

A strict hygienic plan was implemented to contain the initial outbreak, including using separate personnel for each floor. No visitors were allowed. All residents were kept in their rooms without social contact between them. Despite isolation, the cats still had access to all areas and to the outside.

At the end of April, residents of the first floor showed typical COVID-19 symptoms. We tested oropharyngeal swab specimens from the cats on April 29 (surveillance day 1) (Appendix Figure 1, panel A). Although 2 cats (K4 and K9) showed negative results, 1 (K8) showed positive results for SARS-CoV-2 RNA by quantitative reverse transcription PCR specific for partial envelope protein gene (Table; Appendix Figure 1, panel C).

Because of epidemiologic connections, we speculated whether $\mathrm{K} 8$ could have been involved in spreading SARS-CoV-2 to the first floor. We isolated the cats in a Biosafety Level 3 facility for surveillance (Appendix Figure 1, panel A) and tested them again on May 4. K8 was positive for SARS-CoV-2 RNA and had lower quantification cycle values (Table; Appendix Figure 1, panels B, C). Cats were housed in single cages during the first 4 days of quarantine (surveillance days 6-10), then moved into 1 combined cage system (surveillance day 11). After 15 days (surveillance day 21), cats were transferred to floor housing under Biosafety Level 3 conditions and permitted free movement and contact. Testing at regular intervals of conjunctival, fecal, and oropharyngeal swab specimens showed that K4 and K9 remained negative, whereas K8 was positive for SARS-CoV-2 RNA until day 21 of surveillance. K8 also had positive quantification cycle values (range 26.338.5; values $<40$ were considered positive) (Appendix Figure 1, panel B) and $\approx 5.7 \times 10^{4}$ to $5.0 \times 10^{3}$ RNA copies/mL (Appendix Figure 1, panel C).

Subsequently, we detected no viral RNA in swab samples through day 73 .

These PCR results demonstrated an extended period of SARS-CoV-2 infection of the positive cat. When serum samples were analyzed for SARSCoV-2-neutralizing antibodies (5), K8 showed a positive titer (range 1:20-1:52) (Appendix Figure 1, panel D). Multispecies ELISA results showed serum antibodies against the receptor-binding domain (5). Titers peaked by day 35 and decreased but remained positive until the end of surveillance (Appendix Figure 1, 
Table. Overview of cat swab specimen and blood sampling regimen for prolonged SARS-CoV-2 RNA shedding from therapy cat after cluster outbreak in retirement home, Germany*

\begin{tabular}{|c|c|c|c|}
\hline Day of surveillance & Sample type & Cq values by $R d R p / R d R p$ gene screen & Cq values by E/E/S gene screen \\
\hline 1 & OPS & ND/ND & ND/35.56/36.15† \\
\hline 6 & OPS & ND/ND & $\mathrm{ND} / 26.34 / 27.06 \dagger$ \\
\hline 7 & OPS & $29.66 / 31.40$ & $30.52 / N D$ \\
\hline 9 & OPS, CS, FS, BS & $37.48 / \mathrm{no} \mathrm{Cq}$ & $36.23 / N D$ \\
\hline 11 & OPS, CS, FS & $30.95 / 34.80$ & $34.66 / \mathrm{ND}$ \\
\hline 13 & OPS, CS, FS, BS & $32.63 / 35.50$ & $35.98 / \mathrm{ND}$ \\
\hline 15 & OPS, CS, FS & $31.17 / 35.10$ & $36.96 / \mathrm{ND}$ \\
\hline 17 & OPS, CS, FS, BS & $33.12 / 36.50$ & $35.92 / N D$ \\
\hline 19 & OPS, CS, FS & No $\mathrm{Cq} / \mathrm{no} \mathrm{Cq}$ & No $\mathrm{Cq} / \mathrm{ND}$ \\
\hline 21 & OPS, CS, FS, BS & No $\mathrm{Cq} / 38.80$ & No $\mathrm{Cq} / \mathrm{ND}$ \\
\hline 28 & OPS, CS, FS, BS & No $\mathrm{Cq} / \mathrm{no} \mathrm{Cq}$ & ND/ND \\
\hline 31 & OPS, CS, FS & No $\mathrm{Cq} / \mathrm{no} \mathrm{Cq}$ & No $\mathrm{Cq} / \mathrm{ND}$ \\
\hline 35 & OPS, CS, FS, BS & No $\mathrm{Cq} / \mathrm{no} \mathrm{Cq}$ & ND/ND \\
\hline 38 & OPS, CS, FS & No $\mathrm{Cq} / \mathrm{no} \mathrm{Cq}$ & ND/ND \\
\hline 42 & OPS, CS, FS, BS & No $\mathrm{Cq} / \mathrm{no} \mathrm{Cq}$ & ND/ND \\
\hline 45 & OPS, CS, FS & No $\mathrm{Cq} / \mathrm{no} \mathrm{Cq}$ & ND/ND \\
\hline 49 & OPS, CS, FS, BS & No $\mathrm{Cq} / \mathrm{no} \mathrm{Cq}$ & ND/ND \\
\hline 69 & BS & No $\mathrm{Cq} / \mathrm{no} \mathrm{Cq}$ & ND/ND \\
\hline 73 & OPS, CS, FS, BS & No $\mathrm{Cq} / \mathrm{no} \mathrm{Cq}$ & ND/ND \\
\hline \multicolumn{4}{|c|}{$\begin{array}{l}\text { "Results are given for virus-positive cat K8. At day 28, serum samples for analysis of blood were collected (in bold). PCRs were performed between day } \\
\text { and day } 6 \text { by using the RealStar SARS-CoV-2 RT-PCR Kit } 1.0 \text { (Altona Diagnostics, https://www.altona-diagnostics.com) for initial diagnosis (E gene } \\
\text { screen and SARS-CoV-2 specific spike gene), and from day } 7 \text { by using an RdRP gene SARS-2-IP4 quantitative real-time PCR (World Health } \\
\text { Organization-recommended assay) and an E gene-specific PCR (see details in Appendix, https://wwwnc.cdc.gov/EID/article/27/7/20-4670-App1.pdf). } \\
\text { The } 2 \text { results in the RdRp and E gene columns indicate that these assays were performed independently in } 2 \text { different laboratories (University of } \\
\text { Veterinary Medicine Hannover and Friedrich-Loeffler Institut). BS, blood sample; CS, conjunctival swab; Cq, quantification cycle; E, envelope; FS, fecal } \\
\text { swab; ND, not done; OPS, oropharyngeal swab; RdRP, RNA-dependent RNA polymerase; S, spike protein; SARS-CoV-2, severe acute respiratory } \\
\text { syndrome coronavirus 2. } \\
\text { †lndicates a third test result for the S gene. }\end{array}$} \\
\hline
\end{tabular}

panel E). K4 and K9 remained SARS-CoV-2 seronegative (Appendix Figure 1, panels D, E).

To examine the effects of potential co-infections, we analyzed common feline viral infections. All cats were negative for feline leukemia virus. However, K8 was positive for feline immunodeficiency virus (FIV)-specific antibodies, and $\mathrm{K} 4$ and $\mathrm{K} 9$ were positive for feline coronavirus-specific antibodies. The marginal serologic reactivity of $\mathrm{K} 8$ indicated that this cat was not previously infected with feline coronavirus (Appendix Figure 2).

SARS-CoV-2 genome sequences obtained from K8 and related human cases in the retirement home ( 1 from the first outbreak and 3 from the second outbreak) differed from each other by 3 ambiguous sites, indicating low-frequency variants within K8, leading to viral quasispecies. Sequences from the second outbreak included a constant $\mathrm{C} \rightarrow \mathrm{T}$ change (Appendix Figure, panel $\mathrm{F}$ ). These data support direct human-to-cat-transmission during the first outbreak but not zoonotic SARS-CoV-2 transmission from $\mathrm{K} 8$ because of the constant viral sequence difference within the second outbreak series.

Our data showed human-to-cat SARS-CoV-2 transmission in a community-acquired cluster outbreak that had multiple infection events. We demonstrated prolonged shedding of SARS-CoV-2 RNA up to day 21 after the first detection, in contrast to a recent study in a naturally infected cat (RNA-positive for 11 days) (6). We hypothesize a longer period of RNA shedding ( $>21$ days) because we do not know the day of infection before the start of cat surveillance. Prolonged SARS-CoV-2 RNA shedding could be related to immune status of individual animals or co-infections or immunosuppression as reported for humans (7-9).

Our sequencing data do not suggest zoonotic spillback from the SARS-CoV-2-infected cat to humans, as reported elsewhere $(3,10)$. However, reinfections, prolonged virus replication, and transmission events in cats cannot be excluded, in particular if one considers emergence of SARS-CoV-2 variants that have potentially increased host range or ability to escape preexisting immunity. Thus, cats should be considered in surveillance and control measures.

\section{Acknowledgments}

We thank Reinhold Schoirer for expert help with initial SARS-CoV-2 diagnosis in the cats; Giuseppe Valenza, Jürgen Christian, and Nelly Scuda for expert help with human SARS-CoV-2 diagnosis; Dirk Höper for expert help in uploading genome sequences; Patrick Zitzow, Bianka Hillmann, Inga Grotha, and Nelia Libowski for excellent technical support; Saskia Oppermann, Darren Markillie, and Monika Berg for dedicated animal care and exceptional support; and Arbor Biosciences for providing SARSCoV-2 baits for virus enrichment.

This study was supported by the German Federal Ministry of Food and Agriculture through the Federal Office for Agriculture and Food (project ZooSeq, grant no. 2819114019). 


\section{About the Author}

Dr. Schulz is a postdoctoral researcher at University of Veterinary Medicine Hanover, Hanover, Germany. Her primary research interests are the pathogenesis and epidemiology of emerging and vector-borne diseases in the wildlife-livestock and human-animal interfaces.

\section{References}

1. Gaudreault NN, Trujillo JD, Carossino M, Meekins DA, Morozov I, Madden DW, et al. SARS-CoV-2 infection, disease and transmission in domestic cats. Emerg Microbes Infect. 2020;9:2322-32. https:/ / doi.org/10.1080/22221751.20 20.1833687

2. Halfmann PJ, Hatta M, Chiba S, Maemura T, Fan S, Takeda M, et al. Transmission of SARS-CoV-2 in domestic cats. N Engl J Med. 2020;383:592-4. https:/ / doi.org/10.1056/ NEJMc2013400

3. Barrs VR, Peiris M, Tam KW, Law PY, Brackman CJ, To EM, et al. SARS-CoV-2 in quarantined domestic cats from COVID-19 households or close contacts, Hong Kong, China. Emerg Infect Dis. 2020;26:3071-4. https://doi.org/10.3201/ eid2612.202786

4. Sit TH, Brackman CJ, Ip SM, Tam KW, Law PY, To EM, et al Infection of dogs with SARS-CoV-2. Nature. 2020;586:776-8. https://doi.org/10.1038/s41586-020-2334-5

5. Wernike K, Aebischer A, Michelitsch A, Hoffmann D, Freuling C, Balkema-Buschmann A, et al. Multi-species ELISA for the detection of antibodies against SARS-CoV-2 in animals. Transbound Emerg Dis. 2020;Nov 15:1-7. https://doi.org/10.1111/tbed.13926

6. Garigliany M, Van Laere AS, Clercx C, Giet D, Escriou N, Huon C, et al. SARS-CoV-2 natural transmission from human to cat, Belgium, March 2020. Emerg Infect Dis. 2020;26:306971. https://doi.org/10.3201/eid2612.202223

7. Yousaf M, Hameed M, Alsoub H, Khatib M, Jamal W, Ahmad M. COVID-19: Prolonged viral shedding in an HIV patient with literature review of risk factors for prolonged viral shedding and its implications for isolation strategies. Clin Case Rep. 2021;9:1397-401. https:/ /doi.org/10.1002/ ccr3.3786

8. Ambrosioni J, Blanco JL, Reyes-Urueña JM, Davies MA, Sued O, Marcos MA, et al.; COVID-19 in HIV Investigators. Overview of SARS-CoV-2 infection in adults living with HIV. Lancet HIV. 2021;8:e294-305. https:/ / doi.org/10.1016/ S2352-3018(21)00070-9

9. Tarhini H, Recoing A, Bridier-Nahmias A, Rahi M, Lambert C, Martres P, et al. Long term SARS-CoV-2 infectiousness among three immunocompromised patients: from prolonged viral shedding to SARS-CoV-2 superinfection. J Infect Dis. 2021;Feb 8:jiab075. https:/ / doi.org/ 10.1093/infdis/jiab075

10. Sailleau C, Dumarest M, Vanhomwegen J, Delaplace M, Caro V, Kwasiborski A, et al. First detection and genome sequencing of SARS-CoV-2 in an infected cat in France. Transbound Emerg Dis. 2020;67:2324-8. https://doi.org/ 10.1111/tbed.13659

Address for correspondence: Asisa Volz, Institute of Virology, University of Veterinary Medicine Hannover, Buenteweg 17, 30559 Hanover, Lower Saxony, Germany; email: asisa.volz@tiho-hannover.de

\section{Effects of COVID-19 Vaccination Timing and Risk Prioritization on Mortality Rates, United States}

\author{
Xutong Wang, Zhanwei Du, Kaitlyn E. Johnson, \\ Remy F. Pasco, Spencer J. Fox, Michael Lachmann, \\ Jason S. McLellan, Lauren Ancel Meyers \\ Author affiliations: The University of Texas at Austin, Austin, \\ Texas, USA (X. Wang, Z. Du, K.E. Johnson, R.F. Pasco, S.J. Fox, \\ J.S. McLellan, L.A. Meyers); The University of Hong Kong, \\ Hong Kong, China (Z. Du); Hong Kong Science and \\ Technology Park, Hong Kong (Z. Du); Santa Fe Institute, \\ Santa Fe, New Mexico, USA (M. Lachmann, L.A. Meyers)
}

DOI: https://doi.org/10.3201/eid2707.210118

During rollout of coronavirus disease vaccination, policymakers have faced critical trade-offs. Using a mathematical model of transmission, we found that timing of vaccination rollout would be expected to have a substantially greater effect on mortality rate than risk-based prioritization and uptake and that prioritizing first doses over second doses may be lifesaving.

Tn December 2020, the US government issued emergency use authorization for two 2-dose severe acute respiratory syndrome coronavirus 2 (SARS-CoV-2) vaccines, both estimated to be $>94 \%$ efficacious in preventing symptomatic coronavirus disease (COVID-19) (1-3). The Advisory Committee on Immunization Practices immediately recommended the prioritization of frontline workers and high-risk subgroups (4). As of February 14, 2021, $\approx 52$ million doses have been administered (5). We used a mathematical model of COVID-19 transmission to evaluate the effects of vaccine timing, risk prioritization, number of doses administered, and uptake rates on population-level mortality rates (Figure).

Focusing on Austin, Texas, USA, we projected COVID-19 deaths over 8 months for both an infection-blocking vaccine that prevents infection upon exposure (assuming 95\% reduction in susceptibility in vaccinated persons) and a symptom-blocking vaccine that prevents symptoms upon infection (assuming $95 \%$ reduction in symptomatic ratio in vaccinated persons). Vaccination would begin on January 15 or February 15, with 10,000 vaccines administered weekly and allocated to cities pro rata. We compare 3 strategies: no priority groups; 1 of 3 priority groups vaccinated before the general public (adults $>65$ years of age, adults who have high-risk underlying 